\title{
Hybrid Material Encounters - Expanding the Continuum of Museum Materialities in the Wake of a Pandemic
}

\author{
Areti Galani, Jenny Kidd
}

One of the starkest implications of the COVID-19 global health emergency is how it has forced a de-prioritization of touch and physicality in our encounters with one another, as well as a wariness about our interactions with the material world. Within museums, materiality - so pressingly at the heart of 'business as usual' - now presents a problem as visiting experiences are being reconfigured with physical distancing in mind and handling collections is severely restricted.

At the same time, we have witnessed a much-hyped 'pivot to digital' across the sector. According to a Network of European Museum Organisations report, this stimulated a significant increase in online visitors during spring 2020, leading to changes in staff tasks to 'add to the digital team.'. As cultural institutions prepare to re-open their premises, the relationship and tension between the physicality of museum experiences and the virtuality of digital engagements is taking centre stage; for instance, in a statement, Luís Raposo, president of ICOM Europe, passionately declared that 'Humans are analog [sic] creatures, not digital', urging museums to continue to be 'spaces where each one [of us] can be confronted with real original materialities' post-pandemic. ${ }^{2}$

We argue that this crisis provides an opportunity to pursue a dialectical relationship between the digital environment and the ambitions expressed in Raposo's statement. As museums and their audiences turned to digital forms of engagement in the absence of physical encounters, we suggest that new hybrid materialities were made possible within and through digital spaces.

Within archaeological discourse, the notion of 'hybrid material culture' has been discussed and critiqued (for example, Silliman 2015) in relation to artefacts produced as a result of the hybridization of techniques, when different cultures (often in colonial contexts) came into contact. Hybridity also features in heritage discourse about interculturality, drawing predominantly on Homi Bhabha's concept of the 'third space' (for example, Schorch 2013). Within media studies (Chadwick 2013; Lindgren 2014; Treré 2019), scholars have applied that understanding of hybridity to confront a series of binaries - such as human/non-human, social/ technological, public/private - as well as to challenge the physical/digital distinction, as we have also seen in the digital humanities (Ortega 2020). However, hybridity as a characteristic of the relationship between digital and material museum engagements has received limited attention in digital heritage studies to date.

Connecting the notion of hybridity with the materiality of museum engagements allows us to bridge the often-polarizing argument between museum materiality and digital engagement, and its implications/ramifications. Hybridity prompts us to think of materiality - both analogue and digital - as relational rather than as a distinct quality of an artefact. This shift also reflects definitions of digital materiality as 'a process of meaning making and knowledge production that emphasises technology-in-practice rather than a technological artifact' (Shep 2016: 323). The emphasis on digital engagement instigated by COVID-19 brought new energy and urgency to these concerns, as these examples demonstrate:

Vignette \#1: On 25 March 2020, as lockdown measures were implemented in countries around the world, J. Paul Getty Museum posed a task for its Twitter followers: 'We challenge you to recreate a work of art with objects (and people) in your home'. The campaign had a widespread response and was taken up by other institutions globally. Here, the Getty Museum encouraged people to 
engage with the material qualities of artworks by mobilizing and manipulating the materiality of household items. In this process, personal re-workings and empathic engagements with the collection emerged in an expanded range of material interactions. These ephemeral material assemblages and encounters with artworks were further motivated by the opportunity to share the outcomes on social media platforms via the hashtags \#gettychallenge and \#gettymuseumchallenge, resulting in an evolving expression of everyday creativity and meaning making around Getty's collections online.

Vignette \#2: Robot Tours in Hastings Contemporary, UK, were developed as part of a pre-existing research initiative to allow individuals at risk of isolation, including due to disability, to experience the gallery through a remotely controlled robot's camera. During the COVID-19 closure, the tours attracted significant interest, prompting a decision to give booking priority to those considered most at risk of isolation. ${ }^{3}$ Although robotic interfaces for remote visits have been explored since the early 2000 s, the popularity of the Robot Tours during the pandemic drew attention to the limitations of physical museum encounters for a significant portion of the population as well as the need to support visitors' agency in remote and digitally-mediated museum encounters.

According to Chadwick (2013: 4), hybridity 'foregrounds complexity, interdependence, and transition', qualities which characterize the digitally mediated encounters above. The Hastings Robot Tours experiment with a hybrid mode of visiting that bridges physical encounters with art and remote visiting, animating the materialities of the respective experiences. The tours urge us to challenge the proliferating use of digital as a mere tool for capturing and representing literal forms of materiality and to revisit the ways we design for, value and make sense of material sensory encounters more broadly.

Hybridity also draws attention to the notion of in-betweenness as 'the cutting edge of translation and negotiation' (Bhabha 1994: 56). It reminds us that materiality is performed (Drucker 2013), in the sense that it emerges through interaction, and therefore, is situated in cultural and technological contexts. For example, when visitors use a mobile heritage application in situ, their social and physical contexts shape, and are being shaped by, the app (Galani and Kidd 2019). As people assemble the materiality of their heritage encounters through a range of digital, analogue, tangible and intangible resources, their visiting experiences transcend traditional articulations of the physical-digital divide and operate on a continuum of materialities.

Material encounters already exist between objects and their digital records in museums - the restrictions to physical access during the pandemic made that co-dependency visible as digital records became the only reachable form of museum objects. Geismar (2018: xxii) argues that 'moments of remediation are more than just processes of translation - they are moments in which knowledge and meaning itself are produced'. As the relationship between objects and digital representations is not just indexical, we should also be mindful of its material implications.

The notion of hybridity, therefore, should not provide an excuse for neglecting the politics of material and digital museum engagement, their contexts and historicity. Rather, such attention is necessary in responding to emerging challenges:

- the long-term call for cultural institutions not only to initiate but also to nurture relationships with content creators and to accommodate resulting outputs, such as the Getty re-creations;

- $\quad$ the unpicking of the perceived neutrality of digital infrastructures, such as content management systems and metadata, which shape inclusionary/exclusionary practices and interpretations of original artefacts; and

- the relationship between the materiality of digital heritage and its environmental impact, which raises concomitant questions about sustainability. 
For institutions, recognizing and working with a continuum of materialities has complex ethical dimensions. Digital environments continue to pose challenges related to accessibility, equality and literacy, which are only more urgent at this time.

Hybridity also brings opportunities; it encourages museum professionals and users to see institutions differently. Hybrids, according to Boscagli (2014: 11), have a peculiar kind of power; they can 'refuse to occupy their assigned space in the grid of meaning and value'. The COVID-19 crisis gave institutions the confidence, as we have briefly demonstrated, to engage more directly with this power, to explore the diverse material implications of digital engagement and to address online audiences as key agents in the production of digitallymediated material encounters.

In museums in the wake of the pandemic - together with the sweeping call for change of the Black Lives Matter protests and debates about the decolonization of our physical surroundings - materiality is likely to remain in predicament. Understanding material encounters as part of a continuum inherently embraces reflexivity, 'flux', 'in-betweenness' and 'liminality' (Chadwick 2013: 5) and is, therefore, fitting for these times.

Received: 30 June 2020

Finally accepted: 7 August 2020

\section{Acknowledgements}

We thank the reviewers and the issue editor.

\section{Notes}

1 NEMO (Network of European Museum Organisations), 'Survey on the Impact of the COVID-19 Situation on Museums in Europe Final Report', 2020: 12. https://www.ne-mo. org/fileadmin/Dateien/public/NEMO documents/NEMO COVID19 Report 12.05.2020. pdf, accessed 24 July 2020.

2 Luís Raposo, 'Museums in Face of the "Perfect Storm"', ICOM Europe Facebook, 15 June 2020. https://www.facebook.com/icomeurope.museums/posts/1456550637858910? $\underline{\text { tn }=K-R}$, accessed 29 June 2020.

3 Museums+Heritage Advisor: News, 'Hastings Contemporary 'Overwhelmed' by Interest in Robot Tours', 16 April 2020. https://advisor.museumsandheritage.com/news/hastingscontemporary-overwhelmed-by-interest-in-robot-tours/, accessed 29 June 2020.

\section{References}

Bhabha, H. (1994) The Location of Culture, London and New York: Routledge.

Boscagli, M. (2014) Stuff Theory: Everyday Objects, Radical Materialism, New York: Bloomsbury Academic.

Chadwick, A. (2013) The Hybrid Media System: Politics and Power, Oxford: Oxford University Press.

Drucker, J. (2013) 'Performative Materiality and Theoretical Approaches to Interface', Digital Humanities Quarterly, 7 (1) http://www.digitalhumanities.org/dhq/vol/7/1.

Galani, A. and Kidd, J. (2019) 'Evaluating Digital Cultural Heritage "in the Wild": The Case for Reflexivity', ACM Journal on Computing and Cultural Heritage (JOCCH), 12 (1) Article 5 https://doi.org/10.1145/3287272.

Geismar, H. (2018) Museum Object Lessons for the Digital Age, London: UCL Press. 
Lindgren, S. (2014) Hybrid Media Culture: Sensing Place in a World of Flows, London and New York: Routledge.

Ortega, E. (2020) 'Media and Cultural Hybridity in the Digital Humanities', PMLA, 135 (1) 159-64.

Schorch, P. (2013) 'Contact Zones, Third Spaces, and the Act of Interpretation', Museum and Society, 11 (1) 68-81.

Shep, S.J. (2016) 'Digital Materiality', in Susan Schreibman, Ray Siemens, John Unsworth, (eds) A New Companion to Digital Humanities, 322-30, Chichester: Wiley-Blackwell.

Silliman, S.W. (2015) 'A Requiem for Hybridity? The Problem with Frankensteins, Purées, and Mules', Journal of Social Archaeology, 15 (3) 277-98.

Treré, E. (2019) Hybrid Media Activism: Ecologies, Imaginaries, Algorithms, London and New York: Routledge.

\section{Authors}

\section{Dr Areti Galani}

Media, Culture, Heritage

Newcastle University

areti.galani@ncl.ac.uk

Dr Areti Galani is a Senior Lecturer in Media, Culture, Heritage at Newcastle University (UK) specializing in digital heritage. In her research, Galani combines heritage and cultural studies with research through design (RtD) approaches to explore the relationship between heritagemaking and digital culture. She has published in both Human Computer Interaction $(\mathrm{HCl})$ and heritage-related peer-reviewed journals and volumes. She co-edited the special issue on 'Evaluation of Digital Cultural Resources' in the ACM Journal on Computing and Cultural Heritage (2019) and is the chief editor and author of the volume European Heritage, Dialogue and Digital Practices (Routledge, 2019). She is a Managing Editor of Museum and Society.

\section{Dr Jenny Kidd}

School of Journalism, Media and Culture

Cardiff University

kiddjc2@cardiff.ac.uk

Dr Jenny Kidd is a Reader in the School of Journalism, Media and Culture at Cardiff University. She researches digital culture with a particular emphasis on immersive and participatory media within museums and heritage sites. In her research she works in close interaction with the cultural and creative sectors. Kidd is the author of Museums in the New Mediascape (Routledge, 2014) and Critical Encounters with Immersive Storytelling (Routledge, 2019), as well as a co-editor of Performing Heritage (MUP, 2011) and Challenging History in the Museum (Ashgate, 2014). She is a Managing Editor of Museum and Society. 